\title{
Rehabilitation of walking for paraplegic patients by means of a treadmill
}

\author{
F Felici ${ }^{1}$, M Bernardi $^{1}$, A Rodio ${ }^{1}$, P Marchettoni $^{1}$, V Castellano ${ }^{2}$ and A Macaluso ${ }^{1}$ \\ ${ }^{1}$ Istituto di Fisiologia Umana, Facoltà di Medicina e Chirurgia, Università degli Studi di Roma 'La Sapienza', Roma, \\ Italia; ${ }^{2}$ IRCCS S. Lucia, Roma, Italia
}

\begin{abstract}
The present study was aimed at investigating the use of a treadmill for ambulation training of paraplegic subjects. To investigate the likely effectiveness of this modality of rehabilitation, six paraplegic patients (three male and three female) were studied, using new generation reciprocating gait orthoses ( $\mathrm{RGO}$ and $\mathrm{ARGO}$ ), in a treadmill training program. Oxygen consumption, heart rate, and pulmonary ventilation were measured when the subjects were walking at their most comfortable speed on the treadmill and on the open field. These measurements were carried out at the beginning of the study and after two and six months of treadmill training. The following findings were significant: the treadmill walking required $30 \%$ less energy than open field ambulation prior to training $(P<0.001)$ and $50 \%$ after training $(P<0.05)$. The most comfortable walking speed was faster on the treadmill than on the open field by $18 \%$ prior to training $(P<0.05)$ and $42 \%$ afterwards $(P<0.05)$. The energy cost was $50 \%$ less after 2 months training on the treadmill $(P<0.05)$ showing that treadmill training can improve the efficiency of over ground ambulation. It can be concluded that the treadmill training improves the RGO/ARGO walking capability, probably both the walking efficiency (short term adaptation) and physical fitness (long term adaptation).
\end{abstract}

Keywords: paraplegic subjects; reciprocating gait orthosis; treadmill; rehabilitation

\section{Introduction}

Paraplegic patients who ambulate with orthoses have high energy costs and this is a major reason for rejection in preference for a wheelchair. ${ }^{1}$ In fact, rejection of braces ranges from 32 to $59 \%^{2-4}$. Limited use for therapeutic exercise, function in the home and workplace, however, appear to justify continued improvement in the development of new orthoses and methods of training.,

The RGO orthosis has been accepted as one of the more popular devices for therapeutic exercise ${ }^{7}$ and several studies of hybrid use offer conflicting results as to increased efficiency. ${ }^{8-10}$ The present study was aimed at investigating the use of the treadmill in the training of paraplegic patients ambulating with new generation reciprocating gait orthoses (RGO and ARGO). We expected an improvement of general fitness and especially of walking efficiency. In order to test this hypothesis the oxygen cost $\left(\dot{\mathrm{VO}}_{2}\right)$ of paraplegic subjects walking on a treadmill and then on free ground was compared before and after a period of treadmill intensive training.

\section{Materials and methods}

\section{Subjects}

Six paraplegic subjects (three male and three female) were selected from patients involved in rehabilitation

Correspondence: Prof. Francesco Felici, M.D. therapy. Their anthropometric characteristics, spinal lesion level, ASIA grade and duration post injury are listed in Table 1. Each patient underwent conventional rehabilitation with an orthosis (RGO/ARGO) for 2 months prior to the study.

\section{Training on the treadmill}

A motor-driven treadmill (Enraf Nonius, Holland) was utilized in order to control speed up to $0.1 \mathrm{~km}$ per hour. Subjects used the treadmill frame and the training period was 2 months.

The treadmill speed was adjusted to the most comfortable speed (MCS) during the first month; initially 5 min walking and $5 \mathrm{~min}$ resting, which was increased to $20 \mathrm{~min}$ walking.

Interval training during the second month increased the speed of the treadmill to produce $80 \%$ of the maximal heart rate in subjects for $30 \mathrm{~s}$. The cycle was repeated several times after the heart rate returned to 120 beats $\min ^{-1}$ for a total of 30 min duration. Six subjects had three training sessions a week for a total of 25 sessions. Four/six patients participated in 6 months of training (Table 1).

\section{Metabolic measurements and cost indices}

Oxygen consumption $\left(\dot{\mathrm{V}}_{2}\right)$, heart rate $(\mathrm{HR})$ and pulmonary ventilation $\left(\dot{\mathrm{V}}_{\mathrm{E}}\right)$ at rest and walking were measured with a telemetric device (K4 Cosmed, Italy) 
Table 1 Subject characteristics

\begin{tabular}{|c|c|c|c|c|c|c|c|}
\hline Subject & Sex & $\begin{array}{l}\text { Age } \\
(y)\end{array}$ & $\begin{array}{c}\text { Stature } \\
(m)\end{array}$ & $\begin{array}{c}\text { Mass } \\
(\mathrm{kg})\end{array}$ & Orthoses & $\begin{array}{l}\text { Lesion } \\
\text { level/ } \\
\text { ASIA } \\
\text { scale }\end{array}$ & $\begin{array}{l}\text { Time between } \\
\text { trauma and } \\
\text { treatment } \\
\text { (months) }\end{array}$ \\
\hline$* 1$ & M & 22 & 1.72 & 50 & ARGO & T12/A & 14 \\
\hline$* 2$ & M & 28 & 1.80 & 80 & ARGO & T5/A & 12 \\
\hline$* 3$ & M & 19 & 1.85 & 72 & RGO & T8/A & 14 \\
\hline$* 4$ & $\mathrm{~F}$ & 27 & 1.69 & 61 & ARGO & $\mathrm{L} 1 / \mathrm{A}$ & 28 \\
\hline 5 & $\mathrm{~F}$ & 31 & 1.60 & 45 & ARGO & $\mathrm{T} 10 / \mathrm{A}$ & 7 \\
\hline 6 & $\mathrm{~F}$ & 28 & 1.54 & 45 & ARGO & $\mathrm{T} 12 / \mathrm{A}$ & 56 \\
\hline
\end{tabular}

*Subjects trained for 6 months

before treadmill training, following 2 months of conventional training. These measures were repeated at 2 months and 6 months of treadmill training. Measurements were made at the most comfortable speed in open field ambulation and on the treadmill.

The walking cost indices were calculated as follows: (1) energy cost index (ECI) (Joule $\mathrm{kg}^{-1}$ $\left.\min ^{-1}\right)=$ energy cost per body mass and time (Joule $\mathrm{kg}^{-1} \min ^{-1}$ ) divided by the progression speed in meters per min $\left(\mathrm{m} \mathrm{min}^{-1}\right)$. (2) heart rate cost index (HRCI) was similarly calculated as cardiac beats per meter of progression (beats $\mathrm{m}^{-1}$ ).

\section{Statistical analysis}

Student's $t$ test for paired data ${ }^{11}$ was used to compare the two kinds of locomotion and the indices before and after the rehabilitation program on the treadmill. A $P$ value of 0.05 was used as level of significance.

\section{Results}

Walking on the treadmill $(\mathrm{T})$ resulted in less expensive walking than occurred on the open field $(F)$. The saving of energy, computed as the difference between ECI on the $(\mathrm{F})$ and ECI on the $(\mathrm{T})$, was $30.5 \%$ before $\left(44.2 \pm 13.5\right.$ vs $\left.30.7 \pm 11.7 \mathrm{~J} \mathrm{~kg}^{-1} \mathrm{~m}^{-1} ; P<0.001\right)$ and $51.3 \%$ after training $\left(32.3 \pm 10.6\right.$ vs $15.7 \pm 2.1 \mathrm{~J} \mathrm{~kg}^{-1}$ $\left.\mathrm{m}^{-1} ; P<0.05\right)$. The saving in HRCI was about $22 \%$ before training $\left(23 \pm 7\right.$ vs $18 \pm 5$ beats $\left.\mathrm{m}^{-1} ; P<0.01\right)$, and $50 \%$ after the training $\left(23 \pm 9\right.$ vs $10 \pm 1$ beats $\mathrm{m}^{-1}$; $P<0.05)$. The MCS was $18 \%$ higher on the (T) than on the $(F)$ at the beginning of the experiment $\left(7.64 \pm 3.28\right.$ vs $\left.9.33 \pm 4.19 \mathrm{~m} \mathrm{~min}^{-1} ; \quad P<0.05\right)$ and $42 \%$ higher after 2 months of training $(8.95 \pm 4.82 \mathrm{vs}$ $\left.15.34 \pm 1.86 \mathrm{~m} \mathrm{~min}^{-1} ; P<0.05\right)$.

After the treadmill training, the efficiency of RGO/ ARGO walking significantly improved both on the $(F)$ and on the (T). The ECI of the (F) after 2 months of treadmill training was $27 \%$ less and this was significant (Table 2). Differences in HRCI and MCS on the $(\mathrm{F})$ after training were not significant, but MCS increased $15 \%$.

If we compare the measurements taken on the $(\mathrm{T})$
Table 2 Comparison of energy cost index (ECI), heart rate cost index (HRCI) and most comfortable speed (MCS) when walking on the open field $(F)$, before and after the training

\begin{tabular}{lccccc}
\hline & $\begin{array}{c}\text { Subject } \\
\text { no. }\end{array}$ & Before & After & $\begin{array}{c}\% \\
\text { diff }\end{array}$ & $\mathrm{P}$ \\
\hline $\begin{array}{l}\mathrm{ECI} \\
\left(\mathrm{J} \mathrm{kg}^{-1} \mathrm{~m}^{-1}\right)\end{array}$ & 6 & $44.2 \pm 13.5$ & $32.3 \pm 10.6$ & 27 & $<0.05$ \\
$\begin{array}{l}\mathrm{HRCI} \\
\left.(\mathrm{b} \mathrm{m})^{-1}\right)\end{array}$ & 6 & $23 \pm 7$ & $23 \pm 9$ & 0 & $\mathrm{NS}$ \\
$\begin{array}{l}\mathrm{MCS} \\
\left(\mathrm{m} \mathrm{min} \mathrm{min}^{-1}\right)\end{array}$ & 6 & $7.64 \pm 3.28$ & $8.95 \pm 4.82$ & 15 & $\mathrm{NS}$ \\
\hline
\end{tabular}

before and after training, we observe that ECI was reduced by $49 \%$, HRCI by $44 \%$ and MCS improved $39 \%$.

After 6 months of training, ECI was $31.5 \pm 11.8 \mathrm{~J}$ $\mathrm{kg}^{-1} \mathrm{~m}^{-1}$ on the $(\mathrm{G})$ and $14.3 \pm 2.9 \mathrm{~J} \mathrm{~kg}^{-1} \mathrm{~m}^{-1}$ on the $(\mathrm{T})$. They did not differ significantly from the ECI measured both on the $(\mathrm{F})$ and on the $(\mathrm{T})$ after 2 months of training. The only parameter that showed significant improvement after prolonged training was MCS, which was $12.8 \pm 7.2 \mathrm{~m} \mathrm{~min}^{-1}$ on the $(\mathrm{F})$ and $29.2 \pm 10.1 \mathrm{~m} \mathrm{~min}^{-1}$ on the $(\mathrm{T})$. Endurance in walking was also greatly increased (about $30 \mathrm{~min}$ ) and this fact correlated with less fatigue reported by patients.

\section{Discussion}

Walking on the treadmill was less expensive in $\dot{\mathrm{VO}}_{2}, \dot{\mathrm{V}} \mathrm{E}$ and HR with respect to open field walking and this fact was evident from the beginning of the treadmill training. These data support the hypothesis that a treadmill can transfer energy to the RGO/ARGO walking subject saving muscular work. The subject grasps the frame which surrounds the treadmill and applies a vincular (reaction) force to the upper part of his body. The moving treadmill applies a friction force to his foot and the two forces exert a torque on the RGO/ARGO hip mechanism, which extends the thigh with respect to the pelvis. The Bowden cables, which link the two hip mechanisms, transmit the movement to the contralateral swinging hip, causing it to flex. 
Therefore, it is sufficient to lift one leg from the treadmill floor to have it moved forward, while the supporting leg is moved backwards. After a 2 month training period the difference between open field and treadmill walking increased. Walking on the treadmill represented a $50 \%$ energy saving as compared to walking on the ground. This fact shows that the patient improved his efficiency to move on the treadmill. Of more practical importance, the patient improved his walking efficiency in the open field, as demonstrated by the comparison of open field walking cost before vs after the training. This is the most important aspect of our study, because the treadmill emerged as an effective training tool for improving $\mathrm{RGO} / \mathrm{ARGO}$ walking efficiency. After 6 months of training, while there is no gain in efficiency, there is some increase in walking speed. As a result we have incorporated treadmill training into the rehabilitation program. It is conceivable other methods of training may achieve increased efficiency, but we only studied the differences before and after a treadmill training program. Therefore, for those patients who are highly motivated and sufficiently disciplined, this method of training offers improved benefit and perhaps improved function in the community, at home and at work. However, because many studies today indicate a high rejection ratio, ${ }^{12,13}$ long term use and the factors which identify appropriate candidates for $\mathrm{RGO} / \mathrm{ARGO}$ require further study (unpublished data).

It is well known that a long period of concentrated training from a physiotherapist can produce improvement in patient function. ${ }^{14}$ The treadmill is an appropriate apparatus to accomplish this effect by means of disciplined exercise. A great advantage of a treadmill $v s$ open field walking is the fact that the first is much less fatiguing, and therefore better accepted by patients. Physiotherapists stated that the treadmill offers the opportunity to focus their attention on the leg performance of paraplegic patients, which helps in training them to walk normally on the ground (for example between the gym parallel bars). In addition, the patient is helped by repetition of the movement to concentrate on moving according to the physiotherapist's advice and to obtain a more symmetrical gait, which means more efficient walking. Another advantage of treadmill training is physical conditioning. Having a finely graded workload allows the physician to select a range of $\mathrm{HR}$ to train the cardiovascular system. Finally, one of the most important advantages of this method is the precise regulation of the speed of the treadmill, which provides the subjects with a challenge. They enjoy walking on the treadmill and having continuous feedback about both their own speed and that of other subjects which motivates them, thus making the therapy more effective. The most important aspect, however, is that on the treadmill patients are required to undergo much more intensive training than when they are trained to walk on a normal pathway.

\section{Acknowledgements}

Our thanks to Dr John F Ditunno Jr, of Thomas Jefferson University Hospital, for reviewing this paper.

\section{References}

1 D'Ambrosia R, Solomonow M, Baratta RV. Current status of walking orthoses for thoracic paraplegics. The Iowa Orthopaedic Journal 1995; 15: $174-181$.

2 Rosman N, Spira E. Paraplegic use of walking braces: a survey. Arch Phys Med Rehabil 1974; 55: 310-314.

3 Mikelberg R, Reid S. Spinal cord lesions and lower extremity bracing: an overview and follow-up study. Paraplegia 1981; 19: $379-385$.

4 Sposito MMM, Casalis MEP, Ferraretto I. Follow-up of paraplegic patients after comprehensive rehabilitation. Paraplegia 1984; 22: $373-378$.

5 Kantor C et al. Report on a conference on motor prostheses for workplace mobility of paraplegic patients in North America. Paraplegia 1993; 31: $439-456$

6 Bernardi M et al. Ergonomy of paraplegic patients working with a reciprocating gait orthosis. Paraplegia 1995; 33: 458-463.

7 Nene AV, Hermens HJ, Zivold G. Paraplegic locomotion: a review. Spinal Cord 1996; 34: 507-524.

8 Hirokawa $\mathrm{S}$ et al. Energy consumption in paraplegic ambulation using the reciprocating gait orthosis and electrical stimulation of the thigh muscles. Arch Phys Med Rehabil 1990; 71: 687-694.

9 Sikes L et al. Energy expenditure of walking for adult patients with spinal cord lesions using the reciprocating gait orthosis and functional electrical stimulation. Spinal Cord 1996; 34: 659-665.

10 Petrofsky JS, Smith JB. Physiologic costs of computer-controlled walking in persons with paraplegia using a reciprocating-gait orthosis. Arch Phys Med Rehabil 1991; 72: 890-896.

11 Sachs L. Applied Statistics. New York, Berlin, Heidelberg, Tokyo: Springer-Verlag 1982.

12 Sykes et al. The reciprocating gait orthosis: Long-term usage patterns. Arch Phys Med Rehabil 1995; 76: 779-783.

13 Thoumie et al. Restoration of functional gait in paraplegic patients with the RGO-II hybrid orthosis. A multicenter controlled study. I. Clinical evaluation. Paraplegia, 1995; 33: $647-653$.

14 Rusk HA. Rehabilitation Medicine: A Textbook on Physical Medicine and Rehabilitation, Mosby Co, St. Louis, 1964. 